\title{
On the Construction of Business English Writing Network Resources
}

\author{
Weilong Huang ${ }^{1, \text { a }}$ \\ ${ }^{1}$ School of Foreign Languages, Neijiang Normal University, Neijiang 641199, China \\ ahuberthuang@126.com
}

Keywords: BE writing; Connectivism; mobile intelligent terminal; interaction

Abstract. The traditional teaching of business English writing (hereafter referred to as BE writing) has been lagging in the construction of resource with many problems, and calls for the construction of $\mathrm{BE}$ writing network resources. Under the guidance of Connectivism, this paper analyzes the practical foundation of constructing $\mathrm{BE}$ writing network resources, and proposes to construct theoretical knowledge module, practical knowledge module and excellence pursuit module via mobile intelligent terminal. The construction of BE writing network resources can give full play to the interaction among students, interaction between teachers and students, interaction between students and resources, and bring new vitality into the traditional classroom teaching.

\section{Introduction}

In traditional classroom teaching, business English teachers, for a variety of reasons, rely on the business English textbooks too much but neglect to construct network business English resources. As a result, the lagging of business English resources becomes inevitable and the overall business English teaching effect is far from satisfactory. BE writing, one of the core compulsory courses for business English majors, aims to cultivate their business English communication and BE writing ability as required by business English practitioners. How to innovate the course of BE writing to improve students' business writing ability has become an important part of the reform of business English teaching. In view of the lagging of BE writing resources and based on the theory of Connectivism, this paper propose to construct the network resources of BE writing, in order to improve the teaching effect of BE writing and strengthen the practical writing ability of business English majors.

\section{The Lagging of BE Writing Resource Construction}

The construction of BE writing resources should be initiated by business English teachers. Though business English teachers have a good command of English language, they generally don't have the education background of business English or business experience. They often follow the traditional language teaching as they have been instructed by their teachers, giving priority to the acquisition of business knowledge rather than the cultivation of business communication and writing skills. They emphasize the lecturing of textbook but neglect to introduce other learning resources, stress the efficiency of classroom learning but neglect the necessity of extracurricular learning. It results in the so-called negative impact of "single textbook" theory. Meanwhile, the construction of business writing textbook is far from satisfactory. The textbooks about BE writing rarely make use of other non-print media, and only $2 \%$ of the materials surveyed are provided with curriculum software or CD-ROM, which is inconsistent with the construction of modern foreign language teaching materials and business writing teaching." [1]

Business English learners not only have to memorize "a large number of BE writing styles, business English terms and vocabulary, business English sentence patterns, business English language culture", but also have to obtain an understanding about "business practices and processes". [2] In information society, business knowledge has the characteristics of non-linearity, half-life and non-closure, but the traditional teaching overstates the construction of linear knowledge, and hardly provides the network resources of real-time and updated business 
knowledge. It not only restrains the student's business vision, but also hinders their motivation of learning business English. Especially in BE writing, to improve students' business communication skills and writing abilities requires students to actively engage in business English learning. Then how to provide students situational writing resources to stimulate students' interest in learning and improve their practical ability becomes the key to the success of BE writing reform.

\section{The Basis of Constructing BE Writing Resource Construction}

Therefore, the reform in the construction of BE writing resources is imperative. In BE writing teaching, it is beneficial to make the best of business English network resources. It can make full use of the students' ubiquitous learning, timely make up for the constraint of limited class hours, and provide situational, immediate and updated writing resources. Besides, it would make up for the construction of linear knowledge, significantly expand their business vision and develop their initiative of interactive learning. Based on Connectivism, this paper proposes to make use of information technologies to provide students with BE writing network resources.

Theoretical Basis. The theory of Connectivism, was first proposed by Canadian scholar George Siemens. It is well known as a new view of learning applicable to the knowledge structure of the Internet age. In Knowing Knowledge, Siemens divides knowledge into hard knowledge and soft knowledge based on the cycle of knowledge update and decline. The learning theory of Connectivism emphasizes the learning of updated soft knowledge. "Learning is to connect the various professional nodes or the formation of information source network", learning is no longer the internal activities of an individual leaner for he can use the new learning tools to obtain information, to maintain the connection between him and other nodes, and to build his own network, and "personal network was continuously expanded and enhanced through the new nodes." [3] Connectivism emphasizes the networking of knowledge nodes in the network information society, emphasizing that learners can use the relevant network to share, update, use, supplement knowledge, which provides a theoretical basis for constructing BE writing network resources.

Realistic Basis. Though the domestically published BE writing textbooks fail to provide with convenient learning platform of network resources, the rapid development of information technologies create an opportunity for the establishment of BE writing network resource platform by teachers themselves. The development of Internet, mobile Internet, and mobile intelligent terminals makes online learning becoming more and more popular. Through QQ, website, micro-blogging, e-mail, WeChat and other channels, students can get access to a vast of amount of quality BE writing resources easily. Take WeChat for example, it is worthy of the fame of the most influential mobile intelligent terminal. It has simple operation, low cost, and high user viscosity, which provides information technology support for the construction of mobile learning platform. WeChat has unparalleled advantages for the construction of business English resource platform. Many function modules, like Official Account, circle of friends, WeChat friends, and WeChat discussion group can be fully utilized to provide network resources and achieve the multiple interactive learning. Meanwhile, with the reduction in the cost of $4 \mathrm{G}$ networks service and the wide application of wireless technology, business English learners can study anytime and anywhere, which facilitates the interaction of students with business English resources. The learners are looking forward to the access to BE writing network resources through such platforms as WeChat. In the following part, the paper will focus on how to construct BE writing network resources.

\section{Construction of Theoretical Knowledge Module}

Theoretical knowledge is the pre-knowledge of BE writing. Due to the limited class hours, it is unrealistic to systematically introduce the relevant business English theory in classroom teaching. Therefore, students need to actively construct theoretical knowledge of BE writing outside the 
classroom. Thus, the teacher can provide students with relevant business theory knowledge on a certain platform. For the sake of easing students' learning anxiety, theoretical knowledge should be fragmented, targeted, generalized, and interesting enough to help them understand. The ultimate goal of BE writing is to use the relevant business theory to complete the BE writing task, so students only need to have a preliminary understanding of business English theory. In the design of theoretical knowledge modules, knowledge map can be used to reduce the complexity of the knowledge system, and knowledge push by means of audio clips, pictures and animation and other ways can promote the students' interest in knowledge acquisition.

In addition, extracurricular learning of fragmented theoretical knowledge will greatly promote the effect of classroom teaching since it reserves for teachers and students more time to interact, communicate, and feedback in the classroom. The teacher can push the knowledge nodes on Official Account of WeChat platform, so that the nodes of targeted, generalized and interesting theoretical knowledge fragments can be connected, used, updated and supplemented by students.

\section{Construction of Practical Knowledge Module}

The course of BE writing aims to cultivate students' practical ability of BE writing, so the acquisition of practical knowledge is very important. Connectivism emphasizes the connection of different knowledge nodes. By introducing various writing cases or projects in business practice, teachers can design practical knowledge module. For different BE writing styles, the teachers can introduce writing cases in reality, be they successful, unsuccessful or unresolved. Successful and unsuccessful writing examples can encourage students to actively reflect on questions and accumulate knowledge about business writing practice. Meanwhile, it is conducive to the construction of immersion learning model, and the cultivation of learners' critical thinking and communication skills. Unresolved writing project requires students to group themselves and perform project design, role distribution, project implementation, project acceptance and project evaluation. This not only practices the students' BE writing skills, but also cultivates their business communication skills and cross-cultural business communication skills. For example, BE writing involves the writing in inquiry, offer, counteroffer, order confirmation letter and other business writing content. To practice their BE writing, the teacher can design the two groups of Company A and Company B that play the roles of buyer and seller respectively. Company A can establish its own WeChat discussion group, in which the company members can have interactive learning, design inquiry structure and details (the opening words, concluding remarks, specific inquiry steps and inquiry notes), make division of project work (each group member will be assigned specific tasks; perform project steps (individual research and individual learning), summarize project results (letter finishing, discussion and revision), and demonstrate project results (inquiry letter sent to Company B by email). Company B, according to the company A's inquiry, adopts the same project process to complete the offer to Company A. Steven Downes argues that the learning theory of Connectivism indicates an open teaching. [4] In traditional learning theory, teachers play the role of the "saint of the classroom" [5], while the learning theory of Connectibvism defines teachers as a facilitator, that is, "the role of teachers has been shifted from a controller of classroom to the influencer who no longer controls the class but influences or shapes the network." [6] In the writing project, the teacher is supposed to play a guiding role, be responsible for the project design and process monitoring, and timely answer solve the questions of the students. In this way, it not only plays the role of promoter and guider advocated by Connectivism, but also reflects the interaction between students and students, students and resources interaction, student and teacher.

\section{Construction of Excellence Pursuit Module}

$\mathrm{BE}$ writing resources is not just a simple matter of link provision and content sharing. Students 
need to construct personalized learning resources. Connectivism emphasizes that teachers and students can co-build learning resources, while excellence pursuit module provides with students a good channel to create and demonstrate their own quality writing resources. It will be a platform for students to practice themselves, display their talent and promote their participation. In BE writing practice, students, either in individual learning and interactive learning, can get access to a variety of network learning resources, but they can also demonstrate their excellent BE writing letters, to strengthen the connection of knowledge nodes. This not only exercises students' practical ability, but also mobilizes students' active participation. Take the textbook Business English Writing published by FLTRP for example, part of writing exercises are not provided with references, so students can share their quality references on the excellence pursuit module. Be it a group task or an individual work, the exercise of error correction and business letter reply require students to think independently or make interactive discussion, so as to achieve satisfactory results. Taking the group task as an example, the teacher can publish the writing task through WeChat Official Account. The student then can set up the temporary discussion group on WeChat, and exchange with each other. They can even have private chat with other students or the teacher if necessary. By establishing excellence pursuit module on WeChat, students can show their excellent performance, which can also be used as a type of writing resources for other students to learn from. The construction of self-created resources like demonstration writing should take into account peer comments, which can facilitate the interaction of students with resources, and interaction among students.

\section{Summary}

In short, the lagging of $\mathrm{BE}$ writing teaching in learning resources calls for the construction of three-dimensional and ecological BE writing resources. This paper expounds on the theoretical basis and realistic basis of constructing BE writing network resources. With the flexible use WeChat Official Accounts, WeChat friends, WeChat group and other functional modules, we can establish theoretical knowledge module, practice knowledge module, excellence pursuit module, open up the connection of different knowledge nodes, and give full play to the interaction between students, interaction between teachers and students, and interaction between students and resources, and bring new vitality into the traditional classroom teaching.

\section{Acknowledgements}

This work was financially supported by "2016 Neijiang Municipal Planning Project for Philosophy and Social Sciences Research”.

\section{References}

[1] Z.S. Mo, W.J. Sun, Research on Current Situation of BE Writing Coursebooks, Foreign Language Education, 5(2010)84.

[2] K.Y. Hu, L.J. Che, BE writing, Beijing: Foreign Language Teaching and Research Press, 2013.

[3] G. Siemens, Connectivism: A Learning Theory for the Digital Age, Instructional technology \&distance learning, 1(2005)3-10.

[4] S. Downes, Connectivism and connective knowledge: Essays on meaning and learning networks, National Research Council Canada.

[5] T. Anderson, J. Dron, Three Generations of Distance Education Pedagogy, The International Review of Research in Open and Distance Learning, 12(2011)80-97.

[6] Z.J. Wang, L. Chen, Learning Theory of Connectivism and Its Latest Developments. Open Education Research, 5(2014)19. 